\title{
Metodologias ativas: uma discussão acerca das possibilidades práticas na educação continuada de professores do ensino superior
}

\author{
Active methodologies: a discussion about practical \\ possibilities in continuing education of university professors
}

Metodologías activas: una discusión sobre las posibilidades prácticas en la formación continua de los profesores universitarios

\section{Nuria Pons Vilardell Camas, Glaucia da Silva Brito*}

\section{Resumo}

Esta pesquisa tem como objeto de estudo a formação continuada de docentes do ensino superior na modalidade de educação a distância em metodologias ativas de aprendizagem. Como questão de pesquisa, tem-se: os professores universitários entendem o processo 
de formação continuada na ação pedagógica que motive o uso de metodologias ativas na prática? O objetivo foi analisar um curso de formação de professores universitários e discutir, sob o ponto de vista deles, seus entendimentos e sobre seu fazer pedagógico. A pesquisa é de abordagem qualitativa, empírica e exploratória e traz a análise temática dos dados coletados em uma única questão feita, no fim de um curso, a 49 professores de uma universidade pública federal. Os principais resultados encontrados mostram que, apesar de o curso ter aprovação dos 49 investigados, ainda é urgente que se faça a formação continuada de professores universitários, para que possam entender e usar metodologias ativas na sua prática.

Palavras-chave: Formação de professores. Educação a distância. Educação continuada. Metodologias ativas de aprendizagem.

\begin{abstract}
This research has as an study object the continuous training of higher education teachers in the distance education modality in active learning methodologies. As a research question, we have the following: do university teachers understand the process of continuous training in pedagogical action that motivates the use of active methodologies in practice? Our goal was to analyze a college professor's training course and debate, from their perspective, their understanding towards their pedagogical action. The approach of this research is qualitative, empirical and exploratory - it brings the thematic analysis of the data collected from one single question asked by the end of a course with 49 teachers from a federal public university. The main results found show that, despite the fact that the course has been approved by the 49 individuals under study, it is still urgent to make the continuous training of university teachers so they can understand and use active methodologies in their practice.
\end{abstract}

Keywords: Teacher training. Distance learning education. Continuing education. Active learning methodologies. 


\section{Resumen}

Esta investigación tiene como objeto de estudio la formación continua de los profesores en la educación superior en la modalidad de educación a distancia en metodologías de aprendizaje activo. Como cuestión de investigación, se tiene: ¿̇los profesores universitarios entienden el proceso de formación continuada en la acción pedagógica que motive el uso de metodologías activas en la práctica? El objetivo fue analizar un curso de formación para profesores universitarios y analizar desde el punto de vista de estos maestros su comprensión a su pedagógica tienen. La investigación es cualitativo, empírica y exploratorio, trae análisis temático de los datos recogidos en una sola pregunta al final de un curso con 49 profesores de una universidad pública federal. Los principales resultados muestran que, aunque el curso cuenta con la aprobación de los 49 investigados, sigue siendo urgente de hacer la formación continua de los profesores universitarios para que puedan comprender y utilizar métodos activos en su práctica.

Palabras clave: Formación de profesores. Educación a distancia. Educación continua. Metodologías de aprendizaje activo.

\section{Introdução}

Este trabalho insere-se na temática que aborda as metodologias ativas no ensino superior na formação continuada de professores universitários e traz, após fundamentação, a análise da experiência produzida no curso de Metodologias de Ensino Superior, realizado pela Coordenação de Políticas de Formação de Professores (COPEFOR), em parceria com a Pró-Reitoria de Gestão de Pessoas e apoio técnico da Coordenação de Educação a Distância (CIPEAD), no ano de 2016, na Universidade Federal do Paraná (UFPR).

O século XXI é marcado pelo viver o mundo digital. Praticamente tudo e todos tecem redes comunicativas e se adaptam, mesmo que caoticamente, às nuvens de um novo mundo extremamente concreto, mas que, se visto sob o prisma da educação, de alguma forma ainda parece abstrato. 
Há muitos anos, abordam-se novas possibilidades didáticas acerca de metodologias que dariam conta desse novo século, repleto de fragilidades. Por essa razão, escolheram-se, na fundamentação, pesquisadores consagrados pela busca dos caminhos metodológicos que se deveriam entender para, conforme ocorresse a evolução, poder aliar a teoria à prática e modificar o ensino superior, tanto na perspectiva de caminhar na construção quanto, como Anastasiou (2001, p. 68) chama atenção, de "condutores do processo de fazer da universidade um espaço de construção de cidadania, de resolução das questões nacionais, de formação profissional qualificada e atualizada". Nesse sentido, eles trazem diferentes propostas de metodologias diferenciadas, que, ainda em fase inicial, auxiliaram no aprofundamento daquilo que hoje é denominado metodologia ativa.

Por metodologias ativas, entendem-se as diferentes formas de desenvolver o processo do aprender que os professores utilizam, com a intenção da formação crítica de futuros profissionais, em várias áreas do saber. Intenciona-se, com sua aplicação, favorecer a autonomia do estudante, despertar a curiosidade e estimular tomadas de decisões individuais e coletivas, advindas das atividades essenciais da prática social e nos contextos do estudante.

Assim, é importante ressaltar que se vive numa sociedade ávida de conhecimento e, portanto, supõe-se que, como Demo (2004, p. 11) afirma, esse mesmo "conhecimento que esclarece, ilumina e questiona é o mesmo que imbeciliza, censura, coloniza". Por isso, também, concorda-se com o autor quando disserta que o professor é figura estratégica, pois tem lugar decisivo, sendo o gestor formativo. Destarte, entende-se que não se está mais discutindo a centralidade conteudista do professor, mas a "reconstrução" do conhecimento, ou seja, não basta apenas ser dador de aulas, mas assumir o "desafio de cuidar da aprendizagem" (DEMO, 2004, p. 11, grifo nosso).

Compete aqui explicar, mesmo que não tomando a profundidade que merece, o que se entende por aprender e o que se concorda quanto ao "cuidar da aprendizagem". Por aprender, compreende-se aquilo que tem a "ver com as mudanças estruturais que ocorrem em nós de maneira 
contingente com a história de nossas interações" (MATURANA, 2002, p. 60). Ao pensar no "cuidar da aprendizagem", tem-se como construção o ato da reconstrução, da política e do emotivo, uma vez que, como aprendentes, refazemos, tentamos descobrir, reconstruímos e podemos criar. "Caso contrário, apenas permanecemos na imitação, cópia, reprodução" (DEMO, 2004, p. 13) do outro.

Aprender não é um ato mecânico, "mas contexto político, no qual a pessoa deixa a condição de objeto para surgir como sujeito dotado de capacidade de alternativas" (DEMO, 2004, p. 13). Portanto, entende-se como parte da ação do aprender o "não aceitar ser massa de manobra, objeto de manipulação, ou ter noção clara de direitos e deveres, e de saber pensar de tal modo que o bem comum possa ser a referência mais importante" (DEMO, 2004, p. 14).

A informação que se manifesta insensível nos visores dos equipamentos que se carregam e estão a um clique dos olhos traz uma mudança, também sensível, no aprender e deveria trazer a mudança no fazer pedagógico. Entretanto, continua-se a ouvir os alunos e orientandos dizendo que não sabem utilizar didaticamente, tampouco verificam, o exemplo do uso pedagógico de ferramentas virtuais em sala de aula. Ingenuamente ou não, culpa-se a falta de formação continuada em metodologias na formação do professor do ensino superior, de forma a superar os receios individuais, aproximar a teoria à prática pedagógica, entre outros.

Nesse sentido, questiona-se: os professores universitários entendem o processo de formação continuada na ação pedagógica que motive o uso de metodologias ativas na prática? Para responder a essa questão, traçou-se como objetivo analisar um curso de formação de professores universitários e relatar, sob o ponto de vista deles, seus entendimentos de novas metodologias para seu fazer pedagógico.

A pesquisa aqui apresentada delimitou uma parte do todo, de maneira a ser possível responder à questão elaborada. Com abordagem qualitativa, empírica e exploratória, faz-se a análise temática dos dados coletados em uma única questão feita a 49 professores de uma universidade 
pública federal, o fim de um curso de educação continuada na modalidade de Ensino a Distância (EaD).

Este trabalho subdivide-se na fundamentação teórica, na construção metodológica, na análise e discussão dos dados coletados e, por fim, nas considerações finais.

\section{Professor universitário e a relação entre ensino e aprendizagem}

Uma das principais questões relacionadas à atuação do professor universitário refere-se à relação entre ensino e aprendizagem e os tipos de metodologia utilizados em sala de aula, fazendo-se necessária a verificação da eficácia e eficiência das práticas docente nesses processos.

O vocábulo "metodologia" deriva do latim methodus, cujo significado é representado como o caminho para a realização de algo. Em outras palavras, é o estudo dos métodos ou, ainda, o estudo dos caminhos para chegar a um determinado objetivo. O método é o processo pelo qual se chega ao conhecimento. Pode-se extrair daqui que a metodologia acaba sendo o entendimento de aplicações de diferentes métodos para produzir ou obter um dado conhecimento. Dessa forma, a metodologia aplicada à prática de ensino pode ser entendida como um campo da pedagogia que se aprofunda na organização da aprendizagem dos alunos e suas devidas validações de aprendizagem.

Não se pretende entrar na discussão iniciada por Masetto (2003), acerca da diferença entre estratégias e técnicas para desenvolver uma metodologia em aula. Para o autor, a "estratégia é uma maneira de se decidir sobre um conjunto de disposições, ou seja, são os meios que o docente utiliza para facilitar a aprendizagem dos estudantes", enquanto a técnica, além dos meios, inclui os recursos "materiais que estão relacionados aos instrumentos utilizados para atingir determinados objetivos" (MASETTO, 2003, p. 88).

Entretanto, interessa um ponto que o autor traz, considerando a Declaração Mundial sobre Educação Superior no Século XXI (1998), que, 
como síntese, convida a refletir sobre os docentes do ensino superior, que deveriam estar "ocupados sobretudo em ensinar [...] a aprender e a tomar iniciativas, ao invés de serem unicamente fontes de conhecimento" (MASETTO, 2003, p. 16). Traz como cerne da questão a necessidade de criar "programas apropriados ao desenvolvimento" (MASETTO, 2003, p. 16) do corpo docente das Instituições de Ensino Superior (IESs). Assim, deixa claro que a questão maior não é se foram cometidos erros até aqui ou se um método é bom ou ruim, mas o fato de o mundo ter mudado, havendo a necessidade, portanto, com as transformações ocorrendo e ocorridas, de modificar metodologicamente o ensino superior e, com isso, a própria ação docente nas IESs, que devem se preocupar com o conhecimento e a formação de profissionais para as próximas décadas.

O repensar a metodologia de aulas advém de abordagens que comprovam que já não se dá conta das mudanças contemporâneas com a atual forma de ensino superior. Kuenzer (2001) anuncia a defasagem, no ensino superior, quanto à abordagem meramente conteudista, visto que a sociedade e a economia desejam um profissional com formação mais complexa. O mundo "passa a exigir o desenvolvimento de competências cognitivas superiores e de relacionamento, tais como análise, síntese, estabelecimento de relações, criação de soluções inovadoras, rapidez de resposta, comunicação clara e precisa" (KUENZER, 2001, p. 17). Para além, vive-se um momento em que é necessário saber trabalhar em equipes, conviver e respeitar diferenças, entender que será desafiado, "enfrentar [...] as mudanças permanentemente" e, sobretudo, preparar os alunos a interpretar e dominar diferentes linguagens e tecnologias, desenvolvendo o "raciocínio lógico-formal aliado à intuição criadora” (KUENZER, 2001, p. 17).

Uma educação conteudista de abordagem da memorização deve ser repensada no sentido do uso do conhecimento científico para a resolução de problemas, sendo notório que, apenas memorizando dados de conteúdo, isso não será atingido. Por essa razão, a educação inicial é tão importante quanto a continuada e preparar o docente é obrigação de uma IES, assim como dar-lhe condições de praticar, em sua ação pedagógica, novas formas de cuidar da aprendizagem. 
Valente, Abib e Kusnik (2007), em sua pesquisa, identificaram os estilos de aprendizagem de alunos e docentes de uma universidade estadual do Paraná, encontrando que $53 \%$ dos alunos gostariam de aprender ativamente, o que os autores chamaram "experimentação ativa", ou seja, aprender com professores que encorajam a aprendizagem experimental (fazendo) e a autodescoberta (pesquisando, encontrando, analisando e sintetizando), de forma a expandir os limites intelectuais. Em contrapartida, 45\% dos professores mostraram predominância no estilo denominado "conceituação abstrata", isto é, ensinar por conceitos e fundamentos em aulas somente expositivas.

Portanto, faz-se necessário entender e aprofundar, nesse contexto temático, a formação de um professor de ensino superior que, além do profundo conhecimento em sua área do saber, tenha o domínio na área pedagógica. É preciso considerar que, além do papel do docente, se tem o papel esperado do aluno. Entretanto, neste trabalho, apenas se abordará o sentido da metodologia no papel de formação do docente, competindo afirmar que não se tem a intenção de fechar a discussão acerca do tema, que é vasto e requer muitos outros aprofundamentos e pesquisas.

\section{Área pedagógica: formação continuada como forma de renovação do ensino superior}

Nóvoa (19--, 2000, 2016) alerta sobre a necessidade de mudanças urgentes no ensino superior, devido às mudanças dramáticas e drásticas pelas quais passa a sociedade, logicamente por se viver em plena era da comunicação tecnológica, conviver e sobreviver ainda numa concepção franco-napoleônica da educação. Isso gera processos confusos e, algumas vezes, camuflados por um teor moderno, repleto de diferentes equipamentos, que, no processo de ensino e aprendizagem, continuam com metodologias preocupadas em profissionalizar o aluno e transmitir organizadamente o conhecimento do docente, que é previamente estabelecido em ementas ultrapassadas.

Esse estilo de educação é criticado por Masetto (2003, p. 12), pois forma o aluno "amparando-se em experiências profissionais de um professor 
que sabe a um aluno que não sabe e não conhece, seguido por uma avaliação que julga se o aluno está apto ou não para exercer aquela profissão", não havendo preocupação em buscar e criar a ciência ou aplicá-la, para entender o antes, representado pela história, e o atual, representado pela possibilidade de aplicar, reaplicar ou criar a partir do conhecimento.

No início das escolas superiores, os professores (em grande maioria, de linhagem europeia) tinham como tarefa "ensinar seus alunos, provenientes da elite, a serem tão bons profissionais quanto eles", ministrando aulas expositivas e as famigeradas palestras acerca de um dado tema, para mostrar, na prática, como se fazia algo corretamente, gerando o que se tem, até hoje, em muitas áreas do conhecimento, de que "quem soubesse, saberia automaticamente ensinar" (MASETTO, 1998, p. 11). Com isso, não havia a necessidade de formação pedagógica do docente universitário (MASETTO, 1998).

A qualidade do trabalho docente - entendido aqui como comunicação, explicações, adaptação e organização curricular, processo de crescimento e desenvolvimento dos alunos quanto ao conhecimento, processo afetivo-emocional, habilidades desenvolvidas, competências desejadas, desenvolvimento de atitudes éticas e valores sociais (MASETTO, 2003) — não era a preocupação daquela época. Entretanto, sabe-se que hoje tampouco o é, em alguns casos.

Retomar a discussão da necessidade de formação continuada para a ação pedagógica do docente de ensino superior é necessário. Isso porque parece ainda forte o entendimento histórico de que, com apenas o conhecimento específico, se faz um professor universitário. A Lei de Diretrizes e Bases (Lei n ${ }^{\circ}$ 9.394/1996), no seu art. 66, quando se refere à preparação para "o exercício do magistério superior" reforça a ideia de que ser mestre ou doutor já é suficiente: "Far-se-á em nível de pós-graduação, prioritariamente em programas de mestrado e doutorado" (BRASIL, 1996). Como observam Pimenta e Anastasiou (2001), há uma espécie de omissão da formação pedagógica do professor para o ensino superior.

Sabe-se que existem diferentes IESs, com missões e intenções diferenciadas. Tardif (2002), Pimenta e Anastasiou (2001), Masetto (1998, 2003) entre outros pesquisadores, alertam acerca de os saberes docentes 
interligarem-se, como Lauxen (2014, p. 147) conclui em sua tese: "Às condições sociais de ensino e de trabalho nas quais o professor exerce sua atividade num dado ambiente institucional, com especificidades quanto a organização, obrigações e normas às quais seu trabalho deve se submeter”. Destarte, por mais que se faça a crítica nas séries iniciais, ensino básico e médio, não se pode esquecer de que também no ensino superior há a dificuldade, já fundamentada, de não se engavetar o conhecimento, de forma a entender o currículo como o caminho a ser construído por muitos pares que dele fazem parte (GOODSON, 2007).

Isso remete ao fato de as metodologias de ensino para a aprendizagem configurarem-se como caminhos a serem percorridos na construção do conhecimento, independentemente ou não do uso de tecnologias, que não podem superar o docente e devem ser entendidas como meios para dotar o processo de aprendizagem. Portanto, parte-se, neste estudo, do princípio de entender o currículo não como a ordenação predeterminada de disciplinas, algumas vezes organizadas para dar conta do número de professores em dada IES, mas como um componente curricular, que se compactua com o processo de aprendizagem, de modo a efetivamente preocupar-se com o profissional que se pretende formar. Deve ancorar as relações daqueles que participam do processo de ensino e aprendizagem (professores e alunos) quanto ao conhecimento, às habilidades, às competências, aos valores e às atitudes dos profissionais que se formarão.

Nesse sentido, as metodologias ativas de ensino e aprendizagem trazem à tona a competência pedagógica do docente no conceber e ser o gestor do currículo, não apenas o "dador" de ementas superadas, na maior parte das vezes pelo próprio tempo social, econômico e político. A metodologia, no pensar docente, deve dar condições da mediação da aprendizagem, nas estratégias e nas técnicas que serão usadas em aula, no processo de avaliação dos alunos e de si próprio, naquilo que Masetto (2003, p. 71) já anunciava como acompanhar "o aprendiz em sua caminhada em direção aos objetivos e às metas propostas". Sabe-se que essa ideia estaria muito mais para o ideal que real, mas é algo que se acredita ser possível de se desenvolver em formações continuadas de docentes do ensino superior. 
O papel do professor, como lembra Nóvoa (2016), estaria ligado ao potencializar a transformação da informação em conhecimento. Principalmente numa sociedade altamente conectada, em que tudo que se deseja ver está a um toque do dedo indicador, tem-se que entender que "o que define a aprendizagem não é saber muito, é compreender bem aquilo que se sabe" (NÓVOA, 2016, s.p.). Ao docente compete desenvolver nos alunos "a capacidade de estudar, de procurar, de pesquisar, de seleccionar, de comunicar. Para isso, o professor é insubstituível" (NÓVOA, 2016). Aqui, é possível incluir a necessidade insuperável de o docente estar letrado, além de cientificamente, também midiática e digitalmente, ou seja, ter as alfabetizações necessárias ao atual século e ao desenvolvimento tecnológico pelo qual se passa.

Entretanto, compete lembrar o que Demo (2004, p. 86) reflete quanto às metodologias necessárias para este século: é preciso que os alunos também deixem a postura passiva de "frequentadores de aula" para poderem cultivar o que ele denomina "espírito científico", ou seja, aprender a manusear fontes para serem capazes de buscar dados, construir narrativas, entender o que leem, a fim de desconstruir e reconstruir por meio de análises e reflexões, aprender a argumentar com o outro sem impor uma única forma de pensar; assim, também se aprende a respeitar aquilo que não está conforme se deseja entender.

\section{Potencialidades da EaD na educação continuada}

As tecnologias podem representar um catalisador de mudanças, por isso aproveitá-las e colocá-las a serviço da formação continuada de professores no ensino superior pode representar o início da quebra de paradigma de seu próprio uso, assim como convertê-las numa forma de aproveitar o tempo do docente e permitir-se experimentar uma profunda reforma nos modelos de aprendizagem, além de colocar uma das temáticas e abordagens de metodologia ativa muito cara nestes tempos: o aprender em grupos e a colaboração.

Muitos docentes, por não terem a oportunidade de experienciar diferentes ferramentas, acabam por não as utilizar. Nesse sentido, ao 
pensar no propósito de trabalhar com metodologias ativas, necessário se fez planejar um curso a distância que abordasse as metodologias de ensino superior, fazendo com que a aprendizagem iniciasse pela experiência de aprender em um meio virtual.

Com base na abordagem da aprendizagem colaborativa, na tentativa de promover, entre os docentes, o que Torres e Irala (2014) citam como práticas dessa metodologia ativa em ambientes virtuais, pensou-se na educação continuada, em que se respeitasse a centralidade no aluno, no caso pesquisado, o docente, de maneira que se modificasse o papel do professor do curso (denominado tutor), entendendo-o como aquele que medeia a situação de ensino e aprendizagem, participa do caminho a ser construído, possibilita a metacognição e sabe desempenhar o papel de mediador "por meio da colaboração, em que os alunos pela troca entre pares se ensinam mutuamente" (TORRES; IRALA, 2014, p. 76).

No curso pesquisado, utilizou-se o Ambiente Virtual de Aprendizagem (AVA) Moodle e pesquisou-se o fórum, na última questão, trazida de forma aberta, possibilitando a participação de todos os docentes, lendo uns aos outros e complementando, se desejassem, suas respostas. Desse modo, pensou-se na proposição, a partir da própria aprendizagem, da construção de uma narrativa coletiva, que se faz a partir do entendimento do outro, de ter participado com o outro, possibilitando criar, recriar, discordar, concordar a partir de argumentos individuais que podem ter sido construídos devido à maturidade intelectual dos participantes, daquilo que se desenhou coletivamente.

Como metodologia do tutor, foi trazida uma versão da concepção de Instrução complexa: pensamento de nível elevado em classes heterogêneas, adaptada das leituras de Freitas e Freitas (2003) e do entender de Torres e Irala (2014). Desse modo, planejou-se que o tutor deveria enfatizar "as capacidades intelectuais múltiplas de todos os alunos da classe. Portanto, têm de ser construídos materiais apropriados e promovida a mudança da organização do espaço escolar e do papel do professor" (TORRES; IRALA, 2014, p. 85), pois os alunos eram todos professores de ensino superior, 
devendo-se motivar a participação com a maturidade necessária para a situação planejada.

Outro ponto da metodologia de instrução complexa que se adaptou no curso foi a criação e adaptação de conteúdos organizados em unidades temáticas (módulos), tendo a ideia-chave em cada uma. As atividades eram realizadas de forma aberta, ou seja, a participação envolvia a pesquisa e reflexão e se estabelecia a possibilidade de trocar a experiência com o outro, mudar o fazer, refazer, trocar coletiva ou individualmente o próprio aprender.

Na próxima seção, apresenta-se o caminho de construção metodológica para a necessária análise dos dados colhidos na questão aqui estudada, ou seja, analisar, na narrativa individual que se permitiu construir, se os docentes participantes entenderam o processo de formação continuada na ação pedagógica que os motivasse no uso de tecnologias na prática.

\section{Caminhos metodológicos}

A fim de analisar o entender do processo de formação continuada, com metodologias diferenciadas, na ação pedagógica, realizou-se a compilação das narrativas dos sujeitos participantes do curso, de maneira a tecer uma análise descritiva no que se refere aos objetivos, com abordagem qualitativa quanto ao problema, por meio da interpretação do discurso imprimido por esses professores.

Sabe-se que os sujeitos traduzem valores e condutas que refletem o local em que se inserem como sujeitos sociais, assim como o assujeitamento ideológico. Por isso, diz-se que somos representações históricas e ideológicas, não havendo neutralidade no discurso; segundo Brandão (1998, p. 49), as narrativas impressas pelos sujeitos representam "um recorte das representações de um tempo histórico e de um espaço social".

Traz-se a intenção de entender o que Fiorin (1999) deixa claro quanto à possível análise de discurso, no sentido de investigar a visão de mundo de uma classe ou categoria social, no caso, docentes de uma 
universidade pública. Portanto, o sentido de ideologia de que se trata aqui é a forma como um sujeito social, sujeito e assujeitado de uma categoria profissional, entende a realidade em que se enquadra e potencializa a aprendizagem para uma mudança metodológica.

\section{População e amostra}

A população da pesquisa compreendeu 49 professores de uma Universidade Federal no estado do Paraná, regularmente matriculados no curso de formação continuada de Metodologias de Ensino Superior, realizado pela COPEFOR, em parceria com a Pró-Reitoria de Gestão de Pessoas e apoio técnico da CIPEAD, com carga horária de cem horas, na modalidade a distância, no segundo semestre de 2016, na UFPR.

A escolha da IES deu-se pela acessibilidade para aplicação da pesquisa e também pela sua significância no âmbito do ensino superior da região. Quanto aos professores, são vinculados a diferentes áreas do saber, assim como de campi também diferentes; por isso, mesmo tendo uma mesma categoria profissional (docentes), representam a heterogeneidade (FREITAS; FREITAS, 2003; TORRES; IRALA, 2014), entendida pelo conhecimento e área de atuação diferentes para a aplicação da metodologia ativa em aula.

O método de amostragem foi intencional e não probabilístico, visto serem professores da universidade; além disso, esses sujeitos de pesquisa já possuem discernimento para analisar e refletir seu próprio aprendizado. Dessa forma, a amostra da pesquisa foi representada pelos respondentes do último fórum do curso, que questionou o aproveitamento dos docentes inscritos (49) acerca do aprendizado realizado no curso. Entretanto, 19 não responderam ao instrumento de coleta de dados, trazendo-se, assim, para a análise 30 respondentes, que, por questões de ordem ética, serão representados por códigos numéricos. Ainda, pelo fato de nem todos terem realmente respondido à pergunta, apresentam-se as narrativas que atenderam ao proposto. 


\section{Procedimentos de coleta dos dados}

Os dados foram coletados no fim do curso, realizado a distância, no segundo semestre de 2016, e analisados por meio de agrupamento de descritores indicando a relação do pensamento do professor à teoria de suporte. Para a coleta dos dados, elaborou-se um instrumento de pesquisa a partir do levantamento feito na literatura. Como a proposta era o respondente ter liberdade para relatar o que ou quanto o curso auxiliava-o a rever sua atuação docente, propôs-se a narrativa individual e foi possibilitada a leitura das as narrativas por todos os componentes.

\section{Entendendo o curso pesquisado}

O curso de Metodologias de Ensino Superior foi projetado para auxiliar o docente a se preparar para desempenhar a função de professor universitário, em um momento relevante da história da educação nacional, no qual o papel social da universidade e sua função política são inquestionáveis. Novos paradigmas, novos valores, novos interesses na/ da sociedade estão a nos desafiar e, ao mesmo tempo, constituem nosso estímulo para melhor exercermos nosso trabalho. Criaram-se como objetivos do curso: (i) possibilitar a reflexão sobre o papel do professor, os desafios da docência universitária, os paradigmas educacionais, as políticas e a legislação da educação superior; (ii) fornecer orientações sobre como realizar a gestão da sala de aula de forma democrática e competente; (iii) destacar o professor como pesquisador de sua prática; (iv) encaminhar os procedimentos para a realização da pesquisa da prática pedagógica.

Planejou-se didaticamente o curso, na intenção de contribuir para que tais objetivos fossem atingidos, criando-se três módulos, caracterizados pela temática da docência no ensino superior, passando pelos paradigmas educacionais, sua ação em sala de aula, a gestão de aula, a pesquisa, o trabalho colaborativo, os desafios da realidade nacional, a avaliação e os instrumentos e técnicas de docência. 


\section{A escolha do método}

Encontrou-se em Lima (2006) a análise das cartas pedagógicas, que compreende que, ao analisar uma experiência de formação de professores, se pode estabelecer, por meio de narrativas, um diálogo com o pesquisador. A autora, inspirada no "texto de Kramer 'Carta a uma professora falando sobre escola e cidadania" (LIMA, 2006, p. 139), relata, considerando sua experiência e comprovação do método, a oportunidade dada para relatar ou refletir acerca de um aprendizado, como tempo de reflexão dos participantes, sujeitos ativos de uma ação pedagógica de formação, que podem registrar, em suas escritas narrativas, os dados necessários a ser analisados e discutidos na pesquisa.

Por essa razão, encontrou-se no método de análise de cartas narrativas a garantia de que, no próprio ambiente de estudo, os docentes participantes tivessem a liberdade da reflexão de seus caminhos de aprendizagem, estando "ansiosos para dizer o que provavelmente tinham receio de falar" (LIMA, 2006, p. 139) pessoalmente às pesquisadoras. Dessa forma, a narrativa que se solicitou no AVA possibilitou, "naquele contexto, um clima de confidência e intimidade, que os preservaria de julgamento" (LIMA, 2006, p. 139).

Para Lima (2006, p. 140), a narrativa pode representar a "voz à maioria dos docentes, possibilitando [...] maior contato com as ideias do professor em formação e de sua relação com o conhecimento e com a leitura que faz da vida e do mundo em que vive".

A autora, fundamentando o método no entendimento de mediação de Vygotsky (1998), estabelece a relação das mediações pela linguagem, dando oportunidade a quem escreve para entender a produção de seu conhecimento, esclarecer os conceitos estudados, promover a comunicação e a motivação. No mesmo sentido, Sousa e Cabral (2015, p. 156) afirmam, ao comprovar em sua pesquisa a resposta narrativa como opção metodológica de pesquisa e de formação de professores, que ela 
insere-se na vertente investigação formação, ao proporcionar aprendizagens, reflexão, revisitação ao passado, questionamentos sobre o presente numa visão prospectiva, permitindo a esses profissionais do ensino a revisão de posturas e crenças que foram se estabelecendo no decorrer da formação e da prática docente.

Como descritores para a análise das narrativas, estabeleceu-se a tríplice dimensão da formação, trazida por Severino (2001):

a) Epistemológica: "a perspectiva do conhecimento. Só se conhece construindo o saber, ou seja, praticando a significação dos objetos" (SEVERINO, 2001, p. 21) — necessidade de aprender, construir ou mudar.

b) Pedagógica: "a perspectiva decorrente de sua relação com a aprendizagem. Ela é mediação necessária para o processo de ensino/aprendizagem" (SEVERINO, 2001, p. 21).

c) Social: "a perspectiva da extensão" (SEVERINO, 2001, p. 21) ultrapassam a dimensão do curso na teoria e prática das aulas.

$\mathrm{Na}$ sequência, subdividiram-se os descritores de análise com partes das narrativas dos docentes, em uma planilha, tendo sido selecionadas 30 delas, da seguinte forma:

a) Epistemológica: foram selecionadas as narrativas que continham rever a prática, refletir a prática, pensar na prática, refazer a prática, as atividades permitiram, possibilitaram, levaram, pesquisar, aprofundar.

b) Pedagógica: foram selecionadas as narrativas que traziam mediação, diálogo.

c) Social: foram selecionadas as narrativas que mostravam o levar o que se aprendeu para a sala de aula e para outros docentes.

d) Metodologia: a metodologia que se aplicou deveria propiciar a liberdade do diálogo entre os alunos, a participação ativa para aprender e demonstrar a liberdade do tempo para a realização.

Com a seleção realizada, houve a discussão dos dados coletados, proposta na seção que segue. 


\section{Análise e discussão dos dados}

Ao selecionar o descritor da dimensão epistemológica do aprender, do cuidar do aprender, da reflexão da prática pedagógica em um curso de educação continuada, as narrativas verbalizaram a reflexão da teoria e da prática, por meio da pesquisa e do argumento de refletir sobre si mesmo. Seguem algumas delas:

D1: Considero que o curso, [...], contribuiu muito em minha formação docente, principalmente por me colocar em contato com muitas diretrizes e conceitos importantes para tornar minhas práticas pedagógicas mais eficientes. Os conteúdos foram atuais, os textos acessíveis e pertinentes e as atividades possibilitaram uma verdadeira prática de reflexão [...] (grifo nosso).

D3: A participação no curso foi muito importante para melhorar meu desempenho como docente, especialmente considerando que sou nova na carreira. O conteúdo é relevante e aplicável, e o material didático é excelente, prático, revisitei alguns tópicos diversas vezes (grifo nosso).

D6: O curso foi primordial para a minha iniciação como docente. Viabilizou conhecimentos desse novo universo e me fez refletir sobre o aluno que desejo formar. Além dos textos para reflexões [...] (grifo nosso).

D11: Acredito que todos os professores, [...], deveriam realizar este curso pois, hoje, vejo que esta formação assume um papel que transcende apenas uma atualização científica, pedagógica e didática, mas tem caráter de criar espaços de participação, reflexão e formação para que o docente aprenda e se adapte a implantação de novas metodologias de ensino (grifo nosso).

D12: Aprendi muito com as leituras dos textos obrigatórios e complementares sugeridos, além das pesquisas que tive que realizar para cumprir as tarefas semanais. [...] A leitura dos apontamentos dos colegas, através do fórum de discussões, na minha opinião, ficou um pouco aquém do resultado que conseguiríamos com um trabalho de grupo (grifo nosso). 
D22: Um dos pontos positivos do curso foi o fato de poder estudar a qualquer hora do dia e não ter que se deslocar até um local para 'assistir' aula, vantagem essa da própria modalidade de ensino da EAD. Dessa forma, usava o horário mais conveniente para mim. Também foi muito proveitosa [...] onde foram discutidos temas bem atuais que possibilitaram a reflexão da prática docente (grifo nosso).

D24: O curso foi bastante proveitoso e aborda dois problemas centrais de nosso departamento: a falta de estimulo nos alunos e sua emancipação como profissionais. Certamente utilizarei o conhecimento provido aqui (grifo nosso).

D28: Estamos sempre discutindo sobre o papel do docente, do discente e de melhorias para um processo de aprendizagem mais efetivo e ler e discutir mais sobre tudo isso foi muito proveitoso (grifo nosso).

É interessante notar que, dos 30 selecionados para a análise, apenas 12 docentes destacam a reflexão dos conceitos tratados no curso como forma potencial de poder repensar seu fazer pedagógico. Portanto, assumir o "cuidar da aprendizagem" (DEMO, 2004, p. 11) de si próprio para a docência ainda parece ser um desafio entre os participantes.

Outro ponto a ser trazido é a visão epistemológica informada por Valente, Abib e Kusnik (2007), na qual, para aprender, o aluno prefere a experimentação ativa, aprender fazendo com os professores e a autodescoberta pela pesquisa, análise e síntese do que aprendeu, de forma a expandir seus limites intelectuais. Observa-se que os docentes do curso realizado não verbalizaram a pesquisa de novos materiais acerca dos temas tratados (NÓVOA, 2016), conformando-se com os conteúdos disponibilizados no AVA, somente sobre eles refletindo, assim como muitos preferiam aulas presenciais para ouvir as palestras (MASETTO, 2003; TARDIF, 2002; VALENTE; ABIB; KUSNIK, 2007), mostrando predominância do estilo denominado "conceituação abstrata", ou seja, ensinar por conceitos e fundamentos, em aulas preferencialmente expositivas.

Como afirmam Pimenta e Anastasiou (2002), no que concerne à omissão da formação pedagógica do professor para o ensino superior, 
apenas a pós-graduação na formação de mestres e doutores não é suficiente para a prática docente.

D25: Foi muito interessante notar que as concepções do professor, a estrutura da sua aula e os mecanismos de avaliação estão fortemente relacionados. Apesar de parecer óbvio, nunca havia feito essa reflexão (grifo nosso).

D27: Este curso me trouxe conhecimentos que não adquiri durante a pós-graduação, e me fez refletir mais sobre o ensino. Ficou claro para mim que o professor além de buscar novos conhecimentos continuamente, deve estar sempre disposto a enfrentar mudanças no seu método de ensino visando o melhor aprendizado dos alunos (grifo nosso).

Ainda, mesmo não assumindo não ter formação pedagógica para ser professor, apenas um docente do curso verbalizou as metodologias tratadas:

D30: O curso foi bastante proveitoso e, de fato, aprendi bastante sobre conceitos pedagógicos que não fizeram parte da minha formação como médico veterinário. No entanto, a metodologia $\mathrm{EaD}$, ao menos na minha concepção, ainda não é tão atrativa quanto o sistema presencial. $\mathrm{Eu}$, por exemplo, me senti extremamente estimulado durante as atividades oficinas, palestras, encontros. Faria todas as atividades, não fossem os compromissos didáticos junto à universidade. Acredito que nas próximas edições do curso seria interessante buscar um modelo híbrido, mesclando EaD e mais encontros presenciais. Dessa forma poderíamos debater melhor os vários conceitos que tivemos a oportunidade de aprender, realizar simulações, comparações metodológicas, etc. Sei que o EaD confere muito mais flexibilidade a todos, mas encontros a cada duas semanas, por exemplo, seriam estimulantes para fixar o conteúdo de maneira mais prática. [...]. Participei de várias atividades e a oportunidade de aprender sobre metodologias ativas de ensino, preparo de vídeo-aulas, uso de dispositivos móveis para fomentar o ensino e a aprendizagem foram fenomenais (grifo nosso).

Ao selecionar o descritor da dimensão pedagógica, uniram-se as narrativas que traziam a mediação na sala de aula, o diálogo e discussão 
das metodologias que poderiam ser usadas pelos docentes, a avaliação e a ementa.

D1: Também considero que a mediação e as intervenções realizadas pela tutora foram sempre de grande valia nesse processo (grifo nosso).

D3: Também gostei da participação do fórum, aprendi e me inspirei com o input dos colegas [...] (grifo nosso).

D6: A forma como foi estruturado o curso, fez com que se tornasse muito produtivo para iniciantes, sem deixar de ser motivador para os colegas com grande experiência (grifo nosso).

D8: Encontrei nas reflexões dos colegas, acalento das minhas inquietações desse novo desafio que é a docência, principalmente na era tecnológica de informação rápida e de crescimento exponencial (grifo nosso).

D17: [...] A leitura dos apontamentos dos colegas, através do fórum de discussões, na minha opinião, ficou um pouco aquém do resultado que conseguiríamos com um trabalho de grupo (grifo nosso).

D26: Embora com bastante tempo na docência, sempre é muito bom rever conceitos, conhecer novas ideais, interagir com outras pessoas $e$, em sua maioria neste curso, mais jovens. A metodologia EaD é desafiadora e estimulante (grifo nosso).

$\mathrm{Na}$ dimensão pedagógica, que poderia comprovar a reflexão epistemológica, houve pouquíssima contribuição, o que faz pensar na necessidade da formação do professor para entender, ouvir e respeitar o outro. Diz, assim, respeito à dimensão refletida por Masetto (2003) e Demo (2004), incluindo as metodologias necessárias para este século, sendo preciso que os alunos também deixem a postura passiva de frequentadores de aula, para poderem cultivar o que se denominou espírito científico, ou seja, construir narrativas, entender o que se ler para poder desconstruir e reconstruir por meio de análises e reflexões, aprender a argumentar com o outro sem impor 
uma única forma de pensar; assim, também se aprende a respeitar aquilo que não está conforme se deseja entender.

Entretanto, há uma narrativa que comprova a necessidade dessa formação pedagógica mais do que urgente:

D30: Gostaria de deixar registrado minha satisfação em ter participado deste curso. Como todos sabem, nós docentes da área de engenharia não temos, durante a graduação, uma formação direcionada ao magistério. Alguns colegas até brincam que não somos professores, mas sim engenheiros transmitindo conhecimento. Acredito que agora não sou mais um engenheiro transmitindo conhecimento, mas sim um professor em início de carreira (grifo nosso).

Ao selecionar o descritor da dimensão social, ou seja, o levar para a própria prática e para outros docentes aquilo que se aprendeu, houve a verbalização de apenas um docente do curso:

D20: Este curso fez-me refletir sobre as minhas práticas de ensino e, ainda, compartilhar as minhas percepções com colegas de profissão de outras áreas e de instituição. Os textos (materiais) utilizados durante o curso são bons e parece que houve um esforço de adequação dos temas discutidos aos desafios do ensino superior. No entanto, senti falta de um encontro presencial com os colegas de turma. [...] Sei que ainda tenho muito que aprender, antes de 'continuar aprendendo com os alunos', como vi durante essa caminhada. Confesso que desde que entrei, aqui surgiu a primeira oportunidade para, por exemplo, ler o projeto pedagógico do curso que leciono (grifo nosso).

Entende-se, com isso, que a formação do professor ainda é algo solitário, individual, e não se oportuniza o diálogo entre os pares, ou seja, a prática das relações humanas e pedagógicas. Devido ao fato de apenas um docente ter se referido à expansão do aprendido, confirma-se o exposto por Masetto (2003), ao mostrar que na prática os docentes de ensino superior, em geral, pouco dialogam com seus alunos e colegas, talvez um resquício da visão tradicional de aula e formação. 
Quanto à seleção do descritor de metodologia do curso, observou-se que, dos 30 respondentes, 26 solicitaram encontros presenciais, mesmo tendo gostado da metodologia utilizada e da possibilidade do curso a distância. A metodologia proposta por Torres e Irala (2014), que permite que as atividades sejam realizadas de forma aberta, a participação com a pesquisa, a reflexão e a possibilidade de trocar a experiência com o outro, para poder até mesmo mudar o fazer, refazer, trocar coletiva ou individualmente o próprio aprender, foi substituída, na maior parte das vezes, pelo trecho "minha atividade didática não me dá tempo dessa participação, mas guardei os textos e relerei".

D8: A interação nos fóruns, em minha opinião, não conseguiu o mesmo objetivo que o diálogo presencial. Por isso, sugiro que haja durante o curso um momento em que a 'turma' se encontre para efetuar trocas ou para a realização de workshops

D4: Confesso que o tempo foi um empecilho para mim pois gastei um tempo maior do que o que havia planejado para estas atividades.

D9: Devido ao nosso ritmo acelerado e pleno de afazeres do dia-a-dia, tive pouca oportunidade de dialogar com os demais que estavam participando do grupo. Mesmo nas questões mais abertas que possibilitavam essa troca, a quantidade de respostas era grande, o que tornava impossível ler todas ou ao menos escolher aleatoriamente uma pequena parte.

A falta de tempo dos docentes foi algo rotineiramente mencionado pelos docentes, ou seja, a gestão além da aula, possibilitando a organização de sua própria aprendizagem, para poder cuidar da aprendizagem de seus alunos. 


\section{Considerações finais}

A pesquisa realizada, com a intenção de responder se os professores universitários entendem o processo de formação continuada na ação pedagógica que motive o uso de metodologias ativas na prática, permite, nesta fase, afirmar que é necessário repensar a formação de mestres e doutores para serem docentes no ensino superior.

Sem sombra de dúvidas, no saber específico de cada um em sua área, todos são competentes, mas, para ser docente, é necessário ter uma formação também específica, que é a da prática pedagógica.

Ao alcançar o objetivo proposto, de analisar um curso de formação de professores universitários e relatar, sob o ponto de vista deles, seus entendimentos de novas metodologias para seu fazer pedagógico, descobriu-se que, mesmo existindo diversificado material científico acerca da formação de professores, tais como metodologias e avaliações, se o professor não é da área pedagógica, dificilmente tem acesso aos textos, tampouco os procuram.

O diálogo, a argumentação embasada na construção do conhecimento, ainda não é uma prática recorrente dos docentes. Acredita-se que, se há um maior número de formações continuadas, poderão acabar perdendo a timidez inicial de participantes e começar a trocar mais informações para construir colaborativamente o conhecimento da prática pedagógica.

É necessário desenvolver mais estudos acerca dessa temática para poder evoluir na formação de futuros profissionais.

\section{Referências}

ANASTASIOU, L. G. Metodologia do ensino na universidade brasileira: elementos de uma trajetória. In: CASTANHO, S.; CASTANHO, M. E. (Org.). Temas e textos em metodologia do ensino superior. Campinas: Papirus, 2001.

BRANDÃO, H. H. N. Introdução à análise do discurso. Campinas: UNICAMP, 1998. 
BRASIL. Lei n. 9.394, de 20 de dezembro de 1996. Estabelece as diretrizes e bases da educação nacional. Diário Oficial da União, Brasília, DF, 23 dez. 1996.

DEMO, P. Professor do futuro e reconstrução do conhecimento. Petrópolis: Vozes, 2004.

FIORIN, J. L. Elementos de análise do discurso: repensando a língua portuguesa. São Paulo: Editora da Universidade de São Paulo, 1999.

FREITAS, L. V.; FREITAS, C. V. Aprendizagem cooperativa. Porto: Asa, 2003.

GOODSON, I. Currículo, narrativa e o futuro social. Revista Brasileira de Educação, Campinas, v. 12, n. 35, p. 241-252, maio/ago. 2007.

KUENZER, A. Z. O que muda no cotidiano da sala de aula universitária com mudanças no mundo do trabalho? In: CASTANHO, S.; CASTANHO, M. E. (Org.). Temas e textos em metodologia do ensino superior. Campinas: Papirus, 2001.

LAUXEN, S. L. A Docência no ensino superior: saberes e práticas. Revista Eventos Pedagógicos, v. 5, n. 3, p. 138-151, ago./out. 2014.

LIMA, M. S. L. Docência e pesquisa em formação de professores: caminhos que se cruzam nas cartas pedagógicas. In: PIMENTA, S. G.; GHEDIN, E.; FRANCO, M. A. S. (Org.). Pesquisa em educação: alternativas investigativas com objetos complexos. São Paulo: Loyola, 2006.

MASETTO, M. T. (Org.). Docência na universidade. Campinas: Papirus, 1998.

MASETTO, M. T. Competência pedagógica do professor universitário. São Paulo: Summus, 2003.

MATURANA, H. Emoções e linguagem na educação e na política. Belo Horizonte: Ed. UFMG, 2002.

NÓVOA, A. S. (Org). Formação de professores e profissão docente. Changing patterns of regulation and power in teacher education: eight country study of reform practices in teacher education. Impresso. 19--.

NÓVOA, A. S. Profissão professor. Porto: Porto, 2000. 
NÓVOA, A. S. A universidade e a educação básica: falando da formação de professores. Aula inaugural do Programa de Pós-Graduação em Educação. Universidade Federal da Bahia, 2016.

PIMENTA, S. G.; ANASTASIOU, L. G. Docência no ensino superior. São Paulo: Cortez, 2002.

SEVERINO, A. J. Metodologia do trabalho científico. 21. ed. São Paulo: Cortez, 2001.

SOUSA, M. G.; CABRAL, C. L. O. A narrativa como opção metodológica de pesquisa e formação de professores. Horizontes, v. 33, n. 2, p. 149-158, jul./dez. 2015. Disponível em: <https://revistahorizontes.usf.edu.br/horizontes/article/ download/149/102>. Acesso em: 4 maio 2017.

TARDIF, M. Saberes e formação profissional. Petrópolis: Vozes, 2002.

TORRES, P. L.; IRALA, E. A. F. Aprendizagem colaborativa: teoria e prática. In: TORRES, P. L. (Org.). Complexidade: redes e conexões na produção do conhecimento. Curitiba: SENARPR, 2014. v. 1.

VALENTE, N. T. Z.; ABIB, D. B.; KUSNIK, L. F. Análise dos estilos de aprendizagem dos alunos e professores do curso de graduação em ciências contábeis de uma universidade pública do estado do Paraná com a aplicação do inventário de David Kolb Contab. Vista \& Revista, v. 18, n. 1, p. 51-74, jan./mar. 2007.

VYGOTSKY, L. S. A formação social da mente. 6. ed. São Paulo: Livraria Martins Fontes, 1998.

Recebido: 12/05/2017

Received: 05/12/2017

Aprovado: 25/05/2017

Approved: 05/25/2017 